\title{
BEING ONLINE DURING COVID-19 AND THE RELATIONSHIP WITH WELL-BEING: NARRATIVES AMONG UNIVERSITY STUDENTS
}

\author{
Simone Rollo ${ }^{1}$, Claudia Venuleo ${ }^{1}$, Lucrezia Ferrante ${ }^{1}$, Claudia Marino ${ }^{2}$, \\ \& Adriano Schimmenti ${ }^{3}$ \\ ${ }^{1}$ Department of History, Society and Human Studies, University of Salento, Lecce (Italy) \\ ${ }^{2}$ Department of Developmental and Social Psychology, University of Padova, Padova (Italy) \\ ${ }^{3}$ Faculty of Human and Social Sciences, University of Enna "Kore", Enna (Italy)
}

\begin{abstract}
During COVID-19 outbreak various technological devices have provided a basis for maintaining social connections with friends, family, work and community networks, and media have reported a global increase in Internet use. Scholars debate whether Internet use represented a resource for well-being or on the opposite a risk for health.

In the frame of Semiotic, Cultural Psychosocial Theory, we argue that the meaning of Internet use and its impact on well-being might depend on semiotic resources people possessed to represent the crisis and to use the Internet in a healthy manner.

The study examines the meanings of being online during the COVID-19 pandemic based on narratives collected from Italian young students $(\mathrm{N}=323$; Mean age $=22.78, \mathrm{SD}=2.70 ; 77.3 \%$ women; $81.9 \%$ living with their parents), recruited by Microsoft Forms online survey during first Italian Lockdown, and explores whether different views of being online related to different connotations of the Internet during the pandemic and different levels of well-being.

Computer-assisted Content Analysis was used to map the main Dimensions of Meaning (DM) characterizing the texts. Then, ANOVA was used to examine (dis)similarities between DM related to Internet connotations (e.g., resource, danger or refuge); Pearson's correlations were computed to examine the relationships between DM and well-being.

Two DM emerged, the first represent the relationship between being online and the daily life context; the second, the Internet functions during the pandemic. Relations between DM, internet connotation and well-being were found.

Findings highlight how a plurality of representations of being online are active in the cultural milieu and their potential role in explaining the different impact of Internet use on well-being during pandemic.
\end{abstract}

Keywords: COVID-19 pandemic, being online, meaning, internet connotation, well-being.

\section{Introduction}

The containment measures of COVID-19 have provided physical isolation as the main way to contrast the diffusion of the virus. All over the world there has been the closure of schools/universities and workplaces and the obligation to stay at home and leave only for primary needs. A relationship between these physical distance measures and the risk of psychosocial distress has been hypothesized (Brooks et al., 2020; Mazza et al., 2020).

In this emergency situation, technology - and being online - is configured as the main way to "be together", but scientific community debates about the role that internet could be assume in terms of well-being or health risks (Boursier et al., 2020). In this sense, at least two visions are possible: from one side, Internet is a resource where people might maintain friendships increasing social support (Nabity-Grover et al., 2020) or collect health information (Canale et al., 2020) in order to be updated on the pandemic and to reduce distress levels relating to health condition knowledge; from the other side, Internet could be experienced as a constraint in the interpersonal, school/academic/work spheres or even as a danger, as it may have exacerbated distress responses, amplified worry and impaired functioning (Schimmenti et al., 2020; Thompson et al., 2017).

In this study, it is recognized that the relationship between the internet and well-being is complex and dynamic and, to our knowledge, no study has examined the meaning of being online during the COVID-19 pandemic from a user perspective. Adopting a Semiotic Cultural Psycho-social Theory 
(SCPT; Venuleo et al., 2020a) it is recognized the meanings that foster and constrain the way people interprets any specific event, object and state of their life (Salvatore et al., 2018). In this framework, individuals interpret what happens in their life in terms of specific affect-laden meanings that are consistent with the symbolic and cultural environment in which their self and their being-in-the-world are grounded (Salvatore et al., 2018; Venuleo et al., 2020b). In these terms, we suggest that the meaning of Internet use and its impact on well-being might depend on the personal and social cultural meanings in terms of how people interpret their being online in a given historical circumstance, that is, the pandemic situation.

\section{Design}

\subsection{Aims and hypothesis}

The study aims to explore the representations (i.e., meanings) related to "being online" during pandemic and their association with well-being levels. We expect that (1) a plurality of representations of being online reflecting people's variability in the categorization of the experience (Salvatore et al., 2018); (2) different views of being online relate to different Internet connotations during the pandemic and different levels of well-being.

\subsection{Participants}

From 1st April to 19th May 2020, the period when the Italian government imposed self-isolation, an anonymous online survey using Microsoft Forms was conducted. A total of 323 questionnaires were collected among Italian university students (Mean age $=22.78, \mathrm{SD}=2.70 ; 77.3 \%$ women; 81.9\% living with their parents).

\subsection{Data collection}

The online questionnaire was administered. It was composed by three sections. (1) An open question - "Being online in the time of COVID-19..." - was chosen to gain access to the people's subjective experience and to capture their ways of making sense of the state of being online. The open text is more likely to work as a "projective stimulus" (Venuleo \& Guidi, 2016). Participants were encouraged to writing down everything that comes to mind with respect to the situation and responding in the manner that is deemed most appropriate, taking into account that the objective of the investigation was to collect people's subjective experience. Subsequently, (2) participants were asked to choose a connotation of their Internet use during the health emergency between "refuge", "danger", "resource", in accordance with literature suggestions (cf. for Internet as refuge: Tzavela et al., 2015; for Internet as resource or danger: Guan \& Subrahmanyam, 2009). In the last section, (3) the overall well-being of participants was detected through the Flourishing Scale (FS; Diener et al., 2010) in the Italian version by Di Fabio (2016).

\subsection{Data Analysis}

Three steps for data analysis:

(1) An automatic procedure for content analysis (Salvatore et al., 2012; Salvatore et al., 2017) performed by T-LAB software (version T-Lab Plus 2020; Lancia, 2020) - was applied to the whole corpus of narrative texts collected from opened question in order to map the main dimensions of meanings underpinning the set of contents. Specifically, Lexical Correspondence Analysis (LCA) - a factor analysis procedure for nominal data (Benzécri, 1973) - was computed in order to extract principal factorial dimensions that describes the juxtaposition of two patterns of strongly associated (co-occurring) lemma (i.e., the citation form - namely, the headword - used in a language dictionary) and that can be interpreted as a marker of a latent dimension of meanings underpinning dis/similarities in the respondents' discourses (Gennaro et al., 2019; Salvatore et al., 2017). In order to compute LCA, the textual corpus of narratives $(\mathrm{N}=323)$ was split into units of analysis $(\mathrm{EC}=546)$, called Elementary Context Units (ECUs) and the lexical forms present in the ECUs categorized according to the "lemma" they belong to $\left(\mathrm{LEM}\right.$ Total $=550 ; \mathrm{LEM}_{\text {Analysis }}=465$; Threshold Selection $\left.=4\right)$. A digital matrix of the corpus was defined, having as rows the ECU, as columns the lemmas and in the cell $\mathrm{x}_{\mathrm{ij}}$ the value ' 1 ' if the $j$ th lemma was contained in the $i$ th ECU, otherwise the $\mathrm{x}_{\mathrm{ij}}$ cell received the value ' 0 ' (Types $=3720$; Occurrences $=19551$ ).

(2) ANOVA was computed by SPSS v22 to examine (dis)similarities related to Internet connotations with regard to dimensions of meaning extracted.

(3) Pearson's correlation was computed by SPSS v22 to examine the relationships between the dimensions of meanings and the levels of well-being. 


\section{Findings}

\subsection{Dimensions of meaning detection}

Examples of lemma associated on the polarity are reported in brackets using italics.

FIRST FACTORIAL DIMENSION. "Being online in the daily life context": Rupture versus Continuity. This dimension opposes two patterns of lemma which we interpret as the markers of two ways of representing the relationship between being online and the daily life context.

(-) Rupture: being online is recounted as something which reflects the rules and restrictive measures imposed on the citizens during the health emergency to ensure health security (city, citizen, service, rule, restriction, security, reason). Lemmas such as power, impose, immediately evokes a sense of imposition and passivity felt in the regulatory relationship established by the government with the citizens and that brings to mind the human, relational and social condition (condition, relationship, social, human, isolation).

( + Continuity: being online emerges as a state that makes it possible to continue academic commitments (online lessons, professor, degree), leisure activities (leisure, pastime, recipe, cooking, TV series, music, movies), and relationships (friend).

SECOND FACTORIAL DIMENSION. "Internet functions during the pandemic": Health emergency versus Daily activities. This dimension opposes two patterns of lemma which we interpret as the markers of two ways of representing the Internet functions.

(-) Health emergency: being online is recounted in its two-sided nature of being at the same time a source of entertainment and distraction (beautiful, pleasant) during the lockdown (restriction, quarantine), and as a source of danger and unpleasant experiences (source, dangerous, panic, distressing), due to disinformation and media alarmism (fake news, alarmism).

$(+)$ Daily activities: the Internet is interpreted as a means of carrying on (continue, participate, to go forward, as opposed to stop) study activities (university, lesson, online lesson, exam, student), work (working, worker), free time (YouTube, recipe).

\subsection{Comparison of Internet connotations on Dimensions of Meaning (ANOVA)}

Significant statistical differences were found on the second dimension extracted (i.e., "Internet function during the pandemic") with respect to Internet connotation (i.e., resource, danger or refuge) $\left(F_{2,298}=5.14 ; \mathrm{p}<.01\right)$. Post-hoc analyses by Bonferroni test showed that the differences concerned the connotations of the Internet as "Resource" and "Refuge" (Mean Difference I $-\mathrm{J}=.28141 ; \mathrm{p}<.01$ ). This result highlights that participants with higher factor scores on the second dimension of meaning (positive polarity: Daily activities) connoted Internet as "resource", whereas participants with lower factor score on the same dimension (negative polarity: Health emergency) connoted the Internet as "refuge".

\subsection{Relation between Dimension of Meaning and Well-Being levels (Pearson's Correlation)}

Significant statistical correlation was found between participants' positioning on the second dimension (i.e., "Internet function during the pandemic") and well-being levels $(r=.12 ; p<.01)$. This result highlights that higher scores on the second dimension (positive polarity: Daily activities) are related to higher well-being levels; whereas lower scores (negative polarity: Health emergency) are related to lower well-being levels.

\section{Discussion}

Different interpretations were identified about what "being online" means during the pandemic. The distribution of the lemma on the semiotic map (i.e., factorial space) defined by the two dimensions of meaning reflects how each polarity captures a way of interpreting being online.

Referring to the first dimension "Being online in the daily life context", from one hand, Internet represents a way to continue own daily life, that is Internet may play a key role in supporting the response to the crisis (Pan et al., 2020; Roy et al., 2020); from the other hand, the "rupture" meaning could be referred to a view of Internet as an amplifier of the social changes and of the "forced" isolation due to emergency measures (Gruber et al., 2020). The analyses show that there is not association between positioning on the first dimension, the Internet connotation and the well-being levels. This finding could be interpret in this way: continuity may be felt as distressing in some cases (e.g., if it is associated to the pressure to maintain the same standard of productivity and efficiency in a changed scenario) and a benefit in others (e.g., if the sense of maintaining meaningful objectives is in the foreground); similarly, rupture 
can acquire the meaning of having lost or of lacking what existed before or also the meaning of an opportunity to reflect on previous choices and their critical impact and to make the future better.

Referring to the second dimension "Internet functions during the pandemic", from one hand, internet is useful for acquiring health information; from the other hand, it offers the possibility of carrying on with daily activities and goals. These different ways of interpreting the Internet functions were related to the different Internet connotations and to different well-being levels. The respondents that recognize the possibility of carrying on their daily activities online tend to connote the Internet as a resource and to show higher well-being levels, offering support for a compensatory social interaction model in a novel at-risk condition (Canale et al., 2020); on the other hand, the respondents that identify the Internet functions related to the health emergency (e.g., information about number of contagion), tend to connote the Internet as a refuge. This is possible probably because internet is experienced as a means to understand what is happening around. In this way it reduces uncertainty showing lower levels of well-being (Gómez-Salgado et al., 2020; Thompson et al., 2017). This result is consistent with the idea that cybercondria - that is excessive/repeated online searches for health information - is associated with increasing levels of health anxiety or distress. Starcevic and colleagues (2020) observed that during public health crises (such as the COVID-19 pandemic) several factors contribute to cybercondria, including fear of a newly identified and little-known disease, difficulty in coping with uncertainty, lack of authority and reliable sources of health information, large amounts of information often confusing, conflicting and constantly updated, and the inability of online health information to provide reassurance. These factors can help fuel a rapid alternation between need to know (fear of not knowing) and a need not to know (fear of knowing) which can interfere with decision-making and related actions during the pandemic and levels of distress.

\section{Conclusion}

In conclusion, the results suggest the use of the Internet and its impact on well-being during the COVID-19 pandemic may depend on the cultural, social and personal meanings attributed to being online that define a connotation and motivation for use.

\section{References}

Benzécri, J. P. (1973). L'analyse des données (Vol. 2, p. 1). Paris: Dunod.

Boursier, V., Gioia, F., Musetti, A., \& Schimmenti, A. (2020). Facing loneliness and anxiety during the COVID-19 isolation: the role of excessive social media use in a sample of Italian adults. Frontiers in Psychiatry, 11, 1380.

Brooks, S. K., Webster, R. K., Smith, L. E., Woodland, L., Wessely, S., Greenberg, N., \& Rubin, G. J. (2020). The psychological impact of quarantine and how to reduce it: rapid review of the evidence. The Lancet, 395 (10227), 912-920.

Canale, N., Marino, C., Lenzi, M., Vieno, A., Griffiths, M., Gaboardi, M., ... \& Santinello, M. (2020). How communication technology helps mitigating the impact of COVID-19 pandemic on individual and social wellbeing: Preliminary support for a compensatory social interaction model. PsyArXiv.

Di Fabio, A. (2016). Flourishing Scale: Primo contributo alla validazione della versione italiana [Flourishing Scale: First contribution to the validation of the Italian version]. Counsel. Giornale Ital. Ric. Appl, 9, 1-17.

Diener, E., Wirtz, D., Tov, W., Kim-Prieto, C., Choi, D. W., Oishi, S., \& Biswas-Diener, R. (2010). New well-being measures: Short scales to assess flourishing and positive and negative feelings. Social indicators research, 97(2), 143-156.

Gennaro, A., Gelo, O., Lagetto, G., \& Salvatore, S. (2019). A systematic review of psychotherapy research topics (2000-2016): a computer-assisted approach. Res. Psychother. 22, 472-485.

Gómez-Salgado, J., Andrés-Villas, M., Domínguez-Salas, S., Díaz-Milanés, D., \& Ruiz-Frutos, C. (2020). Related health factors of psychological distress during the COVID-19 Pandemic in Spain. International Journal of Environmental Research and Public Health, 17(11), Article 3947.

Gruber, J., Prinstein, M., Abramowitz, J. S., Albano, A. M., Aldao, A., Borelli, J., \& ...Weinstock, L. (2020). Clinical Psychological Science's Call to Action in the Time of COVID-19. PsyArXiv.

Guan, S. S. A., \& Subrahmanyam, K. (2009). Youth Internet use: risks and opportunities. Current opinion in Psychiatry, 22(4), 351-356.

Lancia, F. (2020). User's Manual: Tools for text analysis. T-Lab version Plus 2020. Available online at: https://www.tlab.it/?lang=it (accessed June 20, 2020). 
Mazza, C., Ricci, E., Biondi, S., Colasanti, M., Ferracuti, S., Napoli, C., \& Roma, P. (2020). A nationwide survey of psychological distress among Italian people during the COVID-19 pandemic: Immediate psychological responses and associated factors. International Journal of Environmental Research and Public Health, 17(9), 3165.

Nabity-Grover, T., Cheung, C. M., \& Thatcher, J. B. (2020). Inside out and outside in: How the COVID-19 pandemic affects self-disclosure on social media. International Journal of Information Management, 55(102188), 1-5.

Pan, S. L., Cui, M., \& Qian, J. (2020). Information resource orchestration during the COVID-19 pandemic: A study of community lockdowns in China. International Journal of Information Management, 54, Article 102143.

Roy, K. C., Hasan, S., Sadri, A., \& Cebrian, M. (2020). Understanding the efficiency of social media-based crisis communication during hurricane sandy. International Journal of Information Systems, 52(2), Article 122060.

Salvatore, S., Fini, V., Mannarini, T., Veltri, G., A., Avdi, E., Battaglia, F., ... Valmorbida, A. (2018). Symbolic Universes between present and future of Europe. First results of the map of European societies' cultural milieu. PLoS ONE, 13(1), e0189885.

Salvatore, S., Gelo, O. C. G., Gennaro, A., Metrangolo, R., Terrone, G., Pace, V., et al. (2017). An automated method of content analysis for psychotherapy research: a further validation. Psychother. Res., 27(1), 38-50.

Salvatore, S., Gennaro, A., Auletta, A. F., Tonti, M., \& Nitti, M. (2012). Automated method of content analysis: a device for psychotherapy process research. Psychother. Res., 22(3), 256-273.

Schimmenti, A., Billieux, J., \& Starcevic, V. (2020). The four horsemen of fear: An integrated model of understanding fear experiences during the COVID-19 pandemic. Clinical Neuropsychiatry, 17(2), 41-45.

Starcevic, V., Schimmenti, A., Billieux, J., \& Berle, D. (2020). Cyberchondria in the time of the COVID-19 pandemic. Human Behavior and Emerging Technologies, September 2020, 1-10.

Thompson, R. R., Garfin, D. R., Holman, E. A., \& Silver, R. C. (2017). Distress, worry, and functioning following a global health crisis: A national study of Americans' responses to Ebola. Clinical psychological science, 5(3), 513-521.

Tzavela, E. C., Karakitsou, C., Dreier, M., Mavromati, F., W lfling, K., Halapi, E., ... \& Tsitsika, A. K. (2015). Processes discriminating adaptive and maladaptive Internet use among European adolescents highly engaged online. Journal of adolescence, 40, 34-47.

Venuleo, C., Gelo, C. G. O., \& Salvatore, S. (2020a). Fear, affective semiosis, and management of the pandemic crisis: COVID-19 as semiotic vaccine. Clinical Neuropsychiatry, 17(2), 117-130.

Venuleo, C., Guidi, M. (2016). Seeking for "otherness". Training to the reflexive Competence. In Reflexivity and Psychology (pp. 245-271). Information Age Publishing.

Venuleo, C., Salvatore, G., Andrisano-Ruggieri, R., Marinaci, T., Cozzolino, M., \& Salvatore, S. (2020b). Steps towards a unified theory of psychopathology: The Phase Space of Meaning model. Clinical Neuropsychiatry, 17(4), 236, 252. 